Research Article

\title{
Determination of Shape Coefficient in Elastic Modulus Estimation with Penetration Test
}

\author{
Tongbin Zhao $\mathbb{D}^{1,2}$ Rui Mao $\mathbb{D}^{1,}{ }^{1,2}$ Kai Fang $\mathbb{D}^{1,2}$ Biwen Zhang $\mathbb{D}^{1,2}$ and Fenghai Yu $\mathbb{D}^{1,2}$ \\ ${ }^{1}$ College of Energy and Mining Engineering, Shandong University of Science and Technology, Qingdao 266590, China \\ ${ }^{2}$ State Key Laboratory of Mining Disaster Prevention and Control Co-Founded by Shandong Province, \\ Ministry of Science and Technology, Shandong University of Science and Technology, Qingdao 266590, China \\ Correspondence should be addressed to Kai Fang; skd994359@sdust.edu.cn
}

Received 28 October 2020; Revised 9 December 2020; Accepted 6 March 2021; Published 16 March 2021

Academic Editor: Hualei Zhang

Copyright ( $\odot 2021$ Tongbin Zhao et al. This is an open access article distributed under the Creative Commons Attribution License, which permits unrestricted use, distribution, and reproduction in any medium, provided the original work is properly cited.

\begin{abstract}
Elastic modulus is a significant parameter in design and construction for rock engineering. Rock penetration test as a convenient method to evaluate the modulus of rocks has a great potential to be used. Based on the elastic theory, the relationship between rock penetration behavior and elastic modulus was established. In order to evaluate the elastic modulus, the shape coefficient is an important parameter to be determined. However, due to many factors, the value of this parameter is still uncertain. To provide a better insight into the shape coefficient and its factors, a series of penetration tests which used several types of rock samples with different sizes were conducted to study the determination of shape coefficient under different conditions. The test results show that sample size influences the shape coefficient, and with the increase in size, the shape coefficient decreases gradually to a stable value. In contrast, confining pressure has less effect on shape coefficient, and in the moderate and low stresses region, a fixed value can be selected for the test. Different types of rocks correspond to different shape coefficients. The shape coefficient of hard rock is higher than that of soft rock. Shape coefficient should be selected reasonably according to the penetration depth in practical application, and the reason, furthermore, why back-calculated shape coefficient deviates from the theoretical value is also discussed.
\end{abstract}

\section{Introduction}

Elastic modulus is an important parameter for rock deformation. In rock engineering, it is also an important basis for the design and construction. In routine practice, the elastic modulus of the rock can be obtained by the uniaxial compressive test of rock specimens. Although the test is simple, it has to be restricted to the use of high-quality core samples and associated sophisticated test equipment [1]. Therefore, a method which can measure the elastic modulus quickly and conveniently is necessary. Several attempts have been made to develop methods to evaluate the elastic modulus indirectly, such as nanoindentation, needle penetration test, point load test, Brazilian splitting test, and so on [2-5]. Moreover the Smith rebound tester and borehole elastic modulus method can also measure the modulus effectively in situ [6,7]. These methods provide alternative approach for the estimation of the rock modulus.
As an easily handled method, the penetration test, which uses a rigid conical indenter to penetrate perpendicularly into the rock and estimate the mechanical properties of the rock based on measured penetration force and depth relationship, has become a popular method [8]. An elastic contact mechanics model can be used to quantify the relationship between the elastic modulus and the deformation characteristics under the penetration load. To evaluate the modulus based on the elastic theory, a shape coefficient should be given according to the shape of indenter. However, the rock is a kind of complex geological material and its deformation characteristics are controlled by many factors. For the penetration test, the behavior of the rock is also influenced by the sample size and confining pressure. It is hard to define shape coefficient as a fixed value based on theoretical solution. Therefore, to give reliable prediction of the elastic modulus for practical application, it is necessary to provide a better insight into the shape coefficient and its factors. 
To answer this question, a series of laboratory penetration tests were conducted to study the values and influence factor of shape coefficient. For this purpose, various types of rock with different size and confining pressure were analyzed. Based on the back-calculated shape coefficients under different conditions from the tests, the determination of shape coefficient under different conditions is discussed. Suggestions are also given to improve the prediction accuracy of elastic modulus based on the penetration test method.

\section{Principle of Elastic Modulus Estimation}

To relate the elastic modulus to the penetration load-depth relationship, a mechanical model incorporating the contact properties between the indenter and the rock is necessary. A local coordinate system is defined by radial and angular variables $(r, \varphi)$. At some distance $r$ from origin, a pressure $P$ acts on a small elemental area (Figure 1). The deformation of pressure on the surface is found from the sum of the deformation due to distributed point load $P$. The mathematical theory of Boussinesq and Hertz elastic contact problem is generalized, and the relationship between elastic modulus of uniform pressure and the deformation of load is shown in the following formula:

$$
u_{z}=\frac{1-v^{2}}{\pi E} \iint_{s} P(r, \phi) \mathrm{d} r \mathrm{~d} \phi,
$$

where $u_{z}$ is the distance of uniform pressure; $S$ is the contact area; $E$ is the elastic modulus, GPa; and $v$ is the Poisson's ratio.

According to different indenter shapes, equation (1) can be defined as ball, cylinder, and cone as follows [9]:

$$
\left.\begin{array}{cl}
\text { Ball: } u_{z} & =\frac{1-v^{2}}{E} \frac{3}{2} p_{m} \frac{\pi}{4 a}\left(2 a^{2}-r^{2}\right) \\
\text { Cylindrical: } u_{z} & =\frac{1-v^{2}}{E} p_{m} \frac{\pi}{2} a \\
\text { Cone: } u_{z} & =\frac{1-v^{2}}{E} p_{m} \pi a
\end{array}\right\}(r \leq a),
$$

where $a$ is the radius of contact area which can be regarded as the radius of indenter.

In order to simplify the calculation for practical operation, a shape coefficient can be defined to represent the difference among the various indenter shapes. Then, the integral of formula (2) can be written as a unified form:

$$
u_{z}=\frac{1-v^{2}}{E} p_{m} \omega_{m} a
$$

where $\omega_{m}$ is the shape coefficient.

Based on theoretical relationship in equation (2), the shape coefficients for ball, cylindrical, and conical indenter are $3 \pi / 4, \pi / 2$, and $\pi$, respectively. For the rock penetration test, conical indenter with a hemispherical tip is usually used

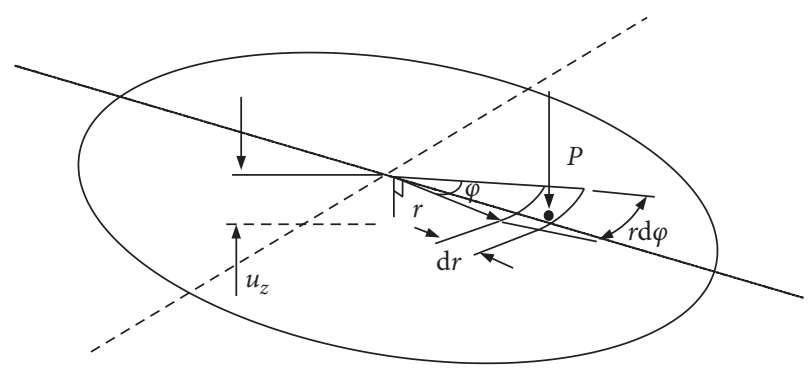

FIgURE 1: A point load acts vertically on semi-infinite half space.

in practice. Because the indentation depth of cone indenter is small, the indenter can be regarded as a ball indenter [10]. With the increase in the penetration depth, the contact between the indenter and the rock will become more complex, and the rock is not completely elastic material, and the actual value of shape coefficient is different from the theoretical value for many different types of rock. In addition, the shape coefficient can be also influenced by the sample size and confining pressure for the penetration test. Therefore, laboratory penetration tests were designed to provide a better insight into the determination of the shape coefficient.

\section{Penetration Tests}

Laboratory penetration tests were conducted to study the effect of rock types, sample size, and confining pressure on the shape coefficient. Different types of rock, including red sandstone, coal, mudstone, grey sandstone, and sandy mudstone, were used in the test. The rock was cut into cube samples with different sizes. To reduce the discrete of the test results, each group of samples is represented by a set of 5 samples.

A servo-controlled loading system and an indenter with a cone angle of $60^{\circ}$ and a tip diameter of $4 \mathrm{~mm}$ ball were utilized to apply the penetration load as shown in Figure 2(a). The size of indenter is suitable for the application of in situ drilling engineering. The sample was placed just below the indenter. Then, the penetration load was applied on the upper surface of the specimen at a load rate of $2.5 \mathrm{~mm} / \mathrm{min}$ until failure occurs. During the process, applied load of the conical indenter was recorded using a computerized data acquisition system. LVDT was used to monitor the indentation depth. To study the influence of in situ pressure on the shape coefficient, an additional lateral loading apparatus (Figure 2(b)) was also used in the test to apply bidirectional confining pressure. The bidirectional loading apparatus was designed as a hollow ring-shaped chamber, which facilitates the application of two independent perpendicular loads. These two loads were applied to the rock specimen by two servo-controlled hydraulic jacks in the apparatus.

\section{Results and Analysis}

4.1. Effect of Size Ratio on Shape Coefficient. For the laboratory penetration test, a range of different sizes of specimen was usually used in the test. Scale effect is an important factor for the application of the test method. The test was 


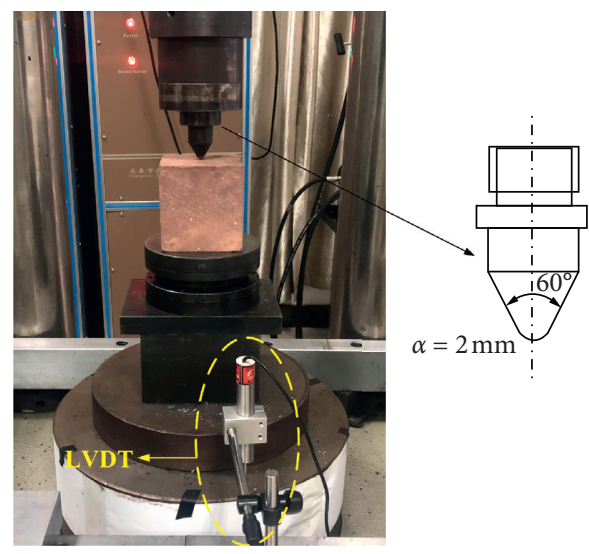

(a)

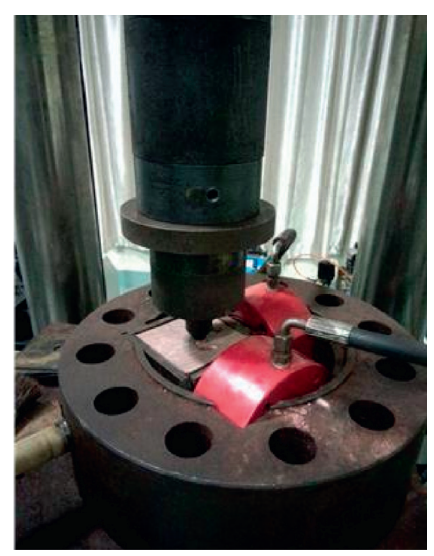

(b)

Figure 2: Testing system.

conducted on finite size of the laboratory specimens rather than semi-infinite surface of rock. Therefore, the shape coefficients back-calculated from the test results differ from the theoretical value. In addition, the size of the specimen will affect the deformation of the rock under penetration load, which leads to the difference in shape coefficient. In order to investigate the influence of sample size on the shape coefficient, a series of red sandstone specimens with different sizes were selected for the penetration test. The mechanical parameters of the red sandstone in the test are shown in Table 1. The relationship of load and penetration depth obtained under different sample sizes is shown in Figure 3. The size ratio in Figure 3 was defined as the ratio of sample side width to the indenter diameter. According to the linear section of the load-penetration depth relationship, real modulus and Poisson's ratio are obtained by the uniaxial test; the shape coefficient under different conditions can be calculated by equation (3). The back-calculated shape coefficients for different size ratios are shown in Figure 4.

Based on the test results, it is noted that the shape coefficient varied over a wide range from 1.6 to 8 for different sample sizes. Great discrepancy between the back-calculated shape coefficient and theoretical value can be observed for the small size samples. With the increase in sample size, the shape coefficient decreases exponentially. When the size ratio reaches 37.5 , it decreases gradually to stable values. According to the cavity expansion model [9], the core zone under the indenter deforms to adapt to the volume of the material replaced by the indenter. The increase in specimen size results in the improvement of the boundary stiffness, which restricts the deformation of the influence area. So, a low shape coefficient can be obtained by using equation (3) for a large sample. However, considering that the influence zone of the penetration load is limited, it is reasonable to assume that the scale effect can be neglected for the sample with a size ratio larger than 37.5. Therefore, a value of shape coefficient of $1.6 \mathrm{can}$ be used for the in situ penetration test. However, for the samples $10 \mathrm{~cm}$ in width, which are most commonly used in the laboratory, a larger shape coefficient should be used in the estimation of the elastic modulus.
4.2. Influence of Confining Pressure on Shape Coefficient. For the in situ penetration test, it is different from the conventional laboratory test because the tested rock mass is under the state of in situ stress. Whether the rock elastic deformation is affected by the confining stress is also a critical and fundamental issue in the application of the in situ penetration test. To give a reasonable prediction of the elastic modulus, the shape coefficient should be modified considering the behavior difference resulting from the confining pressure. In order to give a better insight into the influence of boundary conditions on the shape coefficient, penetration tests of $100 \mathrm{~mm}$ red sandstone under different confining pressures were conducted. The back-calculated shape coefficient was calculated in the same way as above, and the results are plotted against the confining pressure as shown in Figure 5.

Due to the influence of rock sample size, the shape coefficient is higher than theoretical value of ball indenter. In comparison with the test with no confining pressure, the back-calculated shape coefficient for the sample under confining pressure is lower. The main reason is that the sample maintains a compress stress state under confining pressure, resulting in difficulty in the penetration of indenter. Then, a higher load-depth relationship can be obtained and induces the decrease in the back-calculated shape coefficient. It indicates that a lower shape coefficient should be used in the in situ penetration test. In addition, it should be noted that the shape coefficient is not significantly affected with the increasing confining pressure. A fixed value of shape coefficient can be selected for the test on the in situ rock mass in the moderate and low stresses region.

4.3. Influence of Rock Types on Shape Coefficient. To study the influence of rock types on the shape coefficient, five different types of rock, red sandstone, grey sandstone, coal, mudstone, and fine sandstone, are selected for the penetration test. All the sample sizes are about $100 \mathrm{~mm}$. The mechanical parameters of various rocks obtained from the standard uniaxial compression test are shown in 
TABLE 1: Mechanical parameters of red sandstone.

\begin{tabular}{lccc}
\hline Parameters & Unconfined compressive strength $\sigma_{c}(\mathrm{MPa})$ & Elastic modulus $E(\mathrm{GPa})$ & Poisson's ratio $v$ \\
\hline Value & 43.07 & 5.67 & 0.32 \\
\hline
\end{tabular}

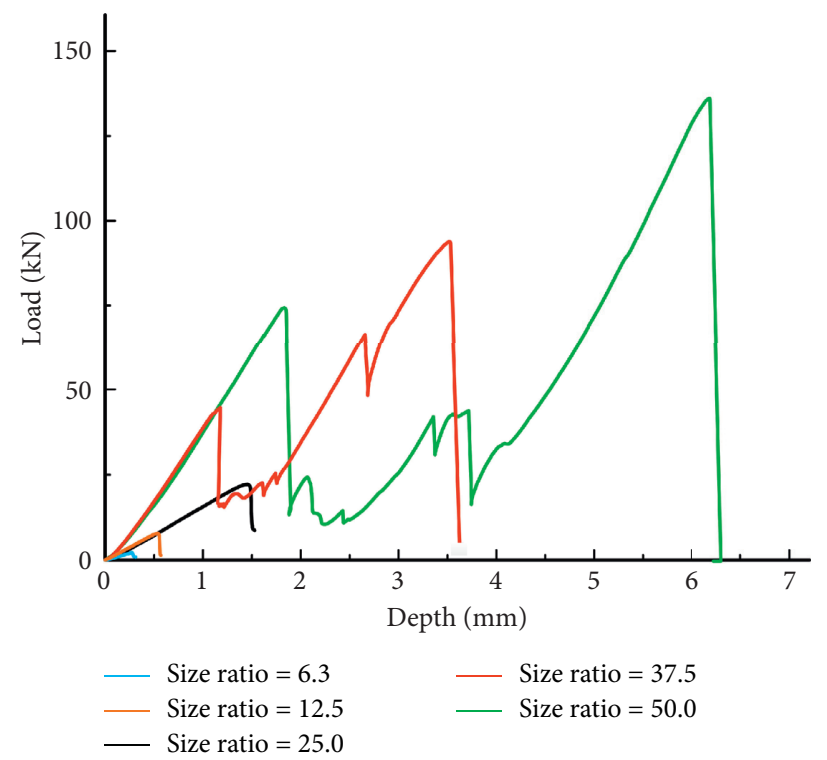

FIgURE 3: Load-penetration depth curves with different size ratios.

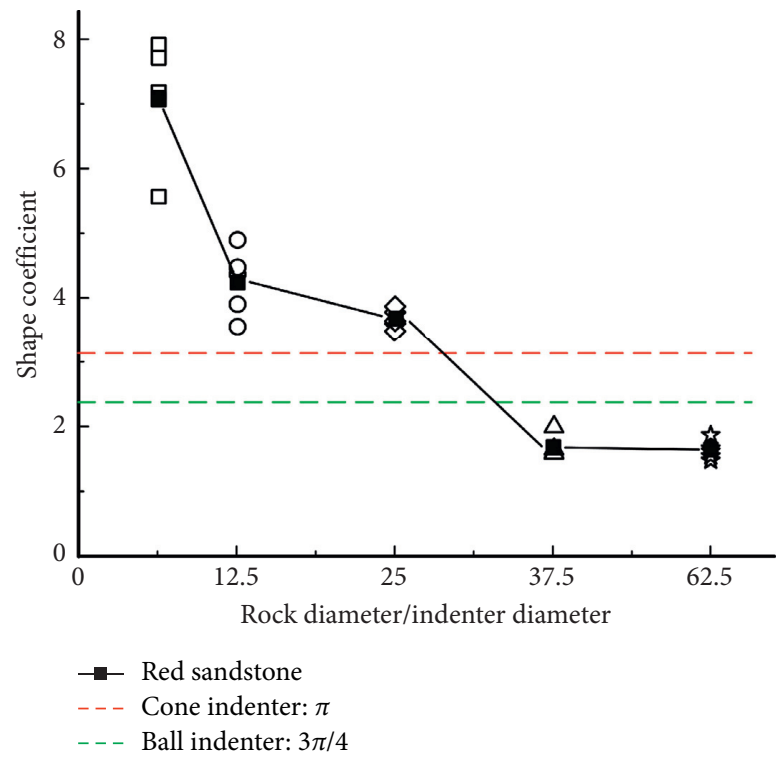

Figure 4: Shape coefficient of different size ratios.

Table 2. The obtained elastic section of load-penetration depth relationship and elastic modulus was used to make a back-calculation of shape coefficient. Furthermore, the influence of Poisson's ratio can be neglected [4]. Poisson's ratio of red sandstone is used for different types of rock. Based on equation (3), the calculated shape coefficients are shown in Figure 6. The back-calculated shape coefficient of red sandstone from the results of another test is also shown in Figure 6 [11].
The result in Figure 6 indicates the discrepancy between the theoretical shape coefficient and back-calculated value. Most of the back-calculated shape coefficients vary between 2 and 4. For the sandstone, a value for $\omega_{m}$ of 3.2 to 3.6 can be obtained from the test results whereas a lower value can be obtained for the soft rock such as coal and mudstone. Considering the influence of rock sample size, for soft rock, the back-calculated shape coefficient is close to the theoretical value, but for sandstone and other rocks, the shape 


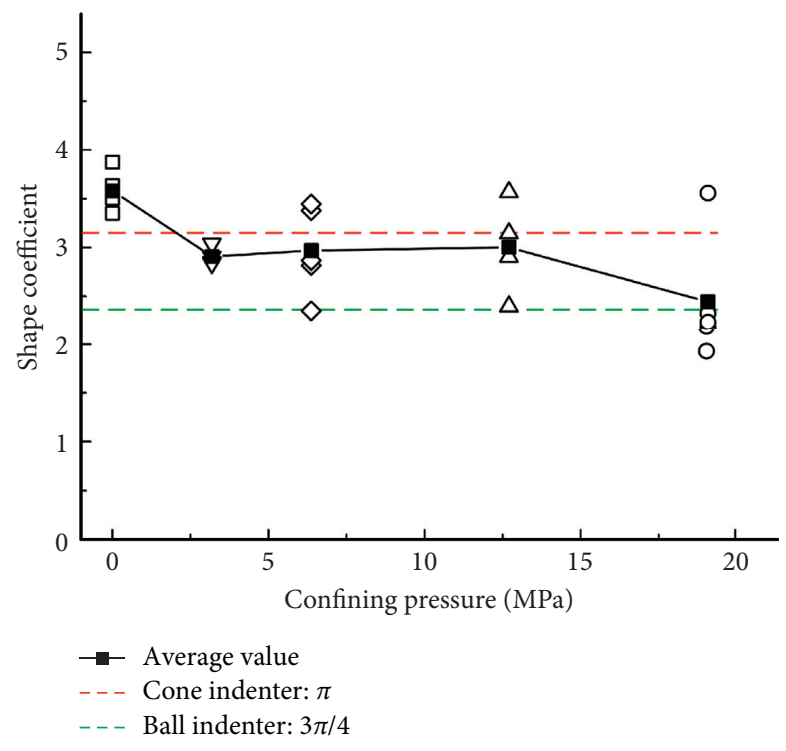

FIgURE 5: Shape coefficient of different size ratios.

TABLE 2: Mechanical parameters of various rocks.

\begin{tabular}{lccc}
\hline Rock & Strength $(\mathrm{MPa})$ & Elastic modulus $(\mathrm{GPa})$ & Average shape coefficient \\
\hline Red sandstone & 43.07 & 5.67 & 3.57 \\
Mudstone & 10.79 & 2.16 & 3.07 \\
Fine sandstone & 98.23 & 9.93 & 3.46 \\
Coal & 8.09 & 1.08 & 2.39 \\
Grey sandstone & 104.09 & 11.43 & 3.23 \\
Red sandstone $[11]$ & 80.56 & 9.70 & 3.53 \\
\hline
\end{tabular}

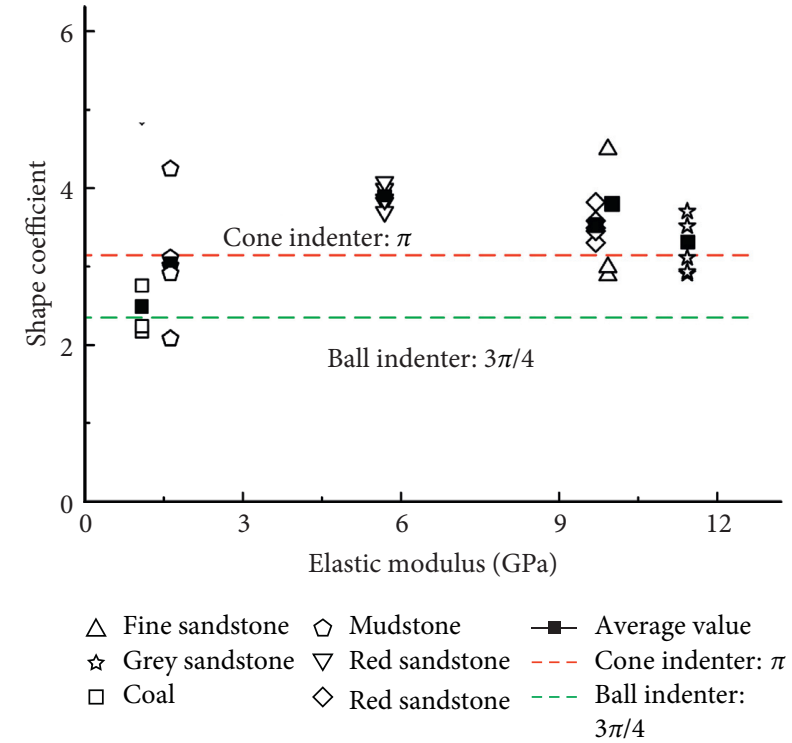

FIGURE 6: Shape coefficient of different types of rock.

coefficient is obviously higher than the theoretical value. It is shown that for soft rock, compared with the uniaxial load deformation characteristics, the load deformation characteristics under penetration load have higher stiffness.

Because of the difference in mineral formations and cementation for different type of rock, it is important to select the appropriate shape coefficient for different types of rock rather than a fixed theoretical value.

\section{Discussion}

The indenter selected in this test is a conical indenter with a hemispherical tip. When the indenter is pressed into a small depth, it can be approximately regarded as a spherical contact. However, when the penetration depth reaches a certain value, its contact radius will increase continuously. It is more appropriate to regard it as a cone indenter. The increase in contact area will lead to the decrease in contact pressure, and then the shape coefficient will increase which was confirmed by the calculation of other test results [12-14]. Therefore, the depth of penetration is an important reference for the selection of shape coefficient in the penetration test.

In the penetration test, the rock under the indenter will be crushed under the penetration load. However, owing to the high contact pressure, the crash zone can be compacted and solidified. The properties of the compacted crash zone will affect the penetration behavior of the indenter. For the soft rock with high porosity, the compacted zone exhibits a higher stiffness response [15-17]. This explains why a lower shape coefficient can be obtained for the soft rock. For the moderate and hard rock, the compacted crash zone may exhibit an equal or higher stiffness response, resulting in the 
difference of back-calculated shape coefficient. This phenomenon can be verified by the experimental results [18]. So, the compacted behavior of the crashed rock should also be considered in the determination of the shape coefficient.

\section{Conclusion}

In the present study, a series of penetration tests were conducted to study the influence of shape coefficient which is used to evaluate elastic modulus with the penetration test. The test results based on commonly used cone indenter can be summarized as follows:

(1) The shape coefficient is related to the size ratio of rock and indenter. As the size ratio increases, the shape coefficient decreases gradually to stable values.

(2) The shape coefficient is not significantly affected by the in situ confining pressure. A fixed value of shape coefficient can be selected for the test on the in situ rock mass in the moderate and low stresses region.

(3) Different types of rock have different shape coefficients rather than a fixed theoretical value. Shape coefficient of soft rock is lower than that of hard rock because of the behavior of the crashed rock. And the shape coefficient should be selected according to the penetration depth.

\section{Data Availability}

The data used to support the findings of this study are available from the corresponding author upon request.

\section{Conflicts of Interest}

The authors declare that they have no conflicts of interest.

\section{Acknowledgments}

This work was supported by the Major Program of Shandong Provincial Natural Science Foundation (ZR2019ZD13), China, the Shandong Province Natural Science Fund (ZR2019QEE015), China, the Major Program of Shandong Provincial Natural Science Foundation (ZR2018ZA0603), and Shandong University of Science and Technology Graduate Science and Technology Innovation Project (SDKDYC190349).

\section{References}

[1] E. T. Brown, Rock Characterization, Testing an MonitoringISRM Suggested Methods, Pergamon, Oxford, UK, 1981.

[2] G. M. Pharr, W. C. Oliver, and F. R. Brotzen, "On the generality of the relationship among contact stiffness, contact area, and elastic modulus during indentation," Journal of Materials Research, vol. 7, no. 3, pp. 613-617, 1992.

[3] Ö. Aydan, "The inference of physico-mechanical properties of soft rocks and the evaluation of the effect of water content and weathering on their mechanical properties from needle penetration tests," Journal of the Agricultural Chemical Society of Japan, vol. 29, no. 5, pp. 707-711, 2012.
[4] T. B. Zhao, K. Fang, and L. Wang, "Estimation of elastic modulus of rock using modified pointload test," Geotechnical Testing Journal, vol. 40, no. 2, pp. 329-334, 2017.

[5] Q. Z. Wang and X. M. Jia, "Determination of elastic modulus, tensile strength and fracture toughness of brittle rocks by using flattened Brazilian disk specimen. Part one: analytical and numerical results," Chinese Journal of Rock Mechanics and Engineering, vol. 21, no. 9, pp. 1285-1289, 2002.

[6] A. Palmström and R. Singh, "The deformation modulus of rock masses-comparisons between in situ tests and indirect estimates," Tunnelling and Underground Space Technology, vol. 16, no. 2, pp. 115-131, 2001.

[7] F. I. Shalabi, E. J. Cording, and O. H. Al-Hattamleh, "Estimation of rock engineering properties using hardness tests," Engineering Geology, vol. 90, no. 3-4, pp. 138-147, 2007.

[8] L. P. Si and H. P. Kang, "In-situ test of surrounding rock strength with bore penetration method," Coal Mining Technology, vol. 11, no. 4, pp. 10-12, 2006.

[9] F. Cripps, Introduction to Contact Mechanics, Springer, Berlin, Germany, 2007.

[10] Z. X. Zhang, M. H. Feng, and S. Q. Kou, "Mechanical analysis of rock intrusion by axisymmetric indenter," Pneumatic Tools for Rock Drilling Machinery, no. 3, pp. 45-53, 1988.

[11] K. Fang, T. Zhao, Y. Zhang, Y. Qiu, and J. Zhou, "Rock cone penetration test under lateral confining pressure," International Journal of Rock Mechanics and Mining Sciences, vol. 119, pp. 149-155, 2019.

[12] H. Y. Jeong, J. W. Cho, S. Jeon et al., "Performance assessment of hard rock TBM and rock boreability using punch penetration test," Rock Mechanics \& Rock Engineering, vol. 49, no. 4, pp. 1-16, 2015.

[13] Ö. F. Erkendirci and B. Z. Haque, "Investigation of penetration mechanics of PW Kevlar fiber reinforced HDPE composites," International Journal of Damage Mechanics, vol. 22, no. 3, pp. 304-322, 2013.

[14] M. Anemangely, A. Ramezanzadeh, B. Tokhmechi et al., "Development of a new rock drillability index for oil and gas reservoir rocks using punch penetration test," Journal of Petroleum Science and Engineering, vol. 166, pp. 131-145, 2018.

[15] Y. L. Tan, W. Y. Guo, T. B. Zhao, and X. J. Meng, "Study on mechanism of instability induced scour in deep coal roadway and "unloading solid" collaborative control," Journal of Coal Industry, vol. 45, no. 1, pp. 66-81, 2020.

[16] T. B. Zhao, M. L. Xing, W. Y. Guo, C. W. Wang, and B. Wang, "Anchoring effect and energy-absorbing support mechanism of large deformation bolt," Journal of Central South University, vol. 28, no. 2, pp. 572-581, 2021.

[17] W. y. Guo, F. H. Yu, Y. L. Tan, and T. B. Zhao, "Experimental study on the failure mechanism of layer-crack structure," Energy Science \& Engineering, vol. 7, no. 6, pp. 2351-2372, 2019.

[18] P.-A. Lindqvist and L. Hai-Hui, "Behaviour of the crushed zone in rock indentation," Rock Mechanics and Rock Engineering, vol. 16, no. 3, pp. 199-207, 1983. 